\title{
Acute Stress Facilitates Hippocampal CA1 Metabotropic Glutamate Receptor-Dependent Long-Term Depression
}

\author{
Francis Chaouloff, ${ }^{1}$ Agnès Hémar, ${ }^{1 *}$ and Olivier Manzoni ${ }^{2 *}$ \\ ${ }^{1}$ Centre National de la Recherche Scientifique Unité Mixte de Recherche 5091 “Physiologie Cellulaire de la Synapse," and 2Inserm Unité 862, Equipe \\ "Physiopathologie de la Transmission et de la Plasticité Synaptique," Institut François Magendie, 33077 Bordeaux, France
}

\begin{abstract}
Acute stress affects NMDA receptor (NMDAR)-dependent synaptic plasticity in the CA1 region of the hippocampus, with long-term potentiation and long-term depression (LTD) being, respectively, diminished and facilitated by acute exposure to stress. Here, we examined whether this facilitatory effect of stress on NMDAR-dependent LTD extends to metabotropic glutamate receptor (mGluR)dependent LTD at Schaffer collateral-CA1 synapses. Application of a low dose (50 $\mu \mathrm{M})$ of the selective group $1 \mathrm{mGluR}$ agonist $(R S)$-3,5dihydroxyphenylglycine (DHPG) promoted LTD in slices from stressed, but not from control, rats. Pretreatment of stressed rats with the glucocorticoid receptor (GR) antagonist RU38486 prevented the facilitation of DHPG-induced LTD (DHPG-LTD), indicating the involvement of corticosterone secretion and, in turn, stimulation of GRs. Finally, pretreatment of slices with an mGluR1, but not an mGluR5, antagonist blunted the sensitizing effect of stress on DHPG-LTD. These results indicate that acute stress, through corticosterone stimulation of GRs, facilitates the expression of mGluR1-dependent DHPG-LTD in the hippocampal CA1 region.
\end{abstract}

Key words: metabotropic glutamate receptor; long-term depression; acute stress; glucocorticoid receptor; hippocampus; CA1

\section{Introduction}

Exposure to acute/chronic uncontrollable stress has major affective (e.g., depression) and cognitive (e.g., impaired learning) consequences (McEwen, 2000; De Kloet et al., 2005). There is overwhelming evidence that numerous stress-elicited changes in behaviors are linked to major modifications in the hippocampal circuitry: according to the duration and intensity of the stressor, these modifications range from functional alterations in synaptic efficacy to gross morphological changes and inhibition of neurogenesis (McEwen, 2000; Kim and Diamond, 2002). In keeping with the tight links established between hippocampal synaptic plasticity, on the one hand, and learning and memory, on the other hand, numerous in vitro and in vivo works have dealt with the consequences of acute stress on NMDA receptor (NMDAR)dependent long-term potentiation (LTP) and/or long-term depression (LTD). In CA1, acute stress impairs high-frequency stimulation-induced LTP while facilitating low-frequency stimulation (LFS)-elicited LTD (Foy et al., 1987; Shors et al., 1989; Kim et al., 1996; Xu et al., 1997). By means of selective ligands for the two classes of corticosteroid receptors, namely the mineralocorticoid receptor (MR) and the glucocorticoid receptor (GR), it

Received March 14, 2007; revised May 10, 2007; accepted May 30, 2007.

This work was supported by grants from the Centre National de la Recherche Scientifique (CNRS), Inserm, and Région Aquitaine. We thank Dr. F. De Bock for help with the slice preparation, Dr. J. P. Pin for advice regarding mGluR pharmacology (both at CNRS and Inserm, Montpellier, France), and Drs. C. Mulle and L. Groc (CNRS, Bordeaux, France) for critical reading of this manuscript.

*A.H. and 0.M. share senior authorship.

Correspondence should be addressed to Dr. Francis Chaouloff, Inserm Unité 862, Equipe AVENIR “Mécanismes Moléculaires de l'Adaptation Comportementale," Institut François Magendie, 146 rue Léo Saignat, 33077 Bordeaux Cédex, France. E-mail: francis.chaouloff@bordeaux.inserm.fr.

D01:10.1523/JNEUROSCI.1150-07.2007

Copyright $\odot 2007$ Society for Neuroscience $\quad$ 0270-6474/07/277130-06\$15.00/0 was shown that GRs mediate the aforementioned effects of acute stress on NMDAR-dependent synaptic plasticity in CA1 (Xu et al., 1998; Yang et al., 2004). This conclusion is in keeping with the respective properties of MRs and GRs to be activated by low and high concentrations of corticosterone [such as those reached during stress (De Kloet, 1991)] and the observation in control slices that GR stimulation by exogenous agonists or by high corticosterone concentrations impedes synaptic potentiation while it enhances LTD in CA1 (Diamond et al., 1992; Coussens et al., 1997; Alfarez et al., 2002; Wiegert et al., 2005). Together, these data clearly indicate that stress, through corticosterone release, is endowed with metaplastic properties (Kim and Diamond, 2002).

At hippocampal CA1 synapses, NMDAR-dependent LTD (NMDA-LTD) coexists with another form of LTD mediated by group 1 metabotropic glutamate receptors (mGluRs) (Bolshakov and Siegelbaum, 1994; Oliet et al., 1997). This mGluR-dependent LTD (mGluR-LTD), which can be elicited pharmacologically by the group 1 mGluR agonist (RS)-3,5-dihydroxyphenylglycine (DHPG), is insensitive to NMDAR blockade and does not occlude NMDA-LTD (Palmer et al., 1997; Fitzjohn et al., 1999; Huber et al., 2000, 2001). Moreover, these two forms of LTD differ with respect to their underlying induction/expression mechanisms, including rapid dendritic protein synthesis dependency/independency (Malenka and Bear, 2004). In keeping with the observation that group 1 mGluR ligands are endowed with potent effects in memory and anxiety tests (Spooren et al., 2003), we thus investigated whether acute stress has any influence on DHPG-induced LTD (DHPG-LTD) at CA1 synapses. The results show that acute stress facilitates DHPG-LTD, an effect mediated by corticosterone stimulation of GRs and dependent on mGluR1 but not mGluR5 activation. 


\section{Materials and Methods}

Animals and stress protocol. Two-week-old Sprague Dawley rat pups and their mothers (Janvier, Le Genest Saint Isle, France) were kept in temperature- and humidity-controlled quarters under a $12 \mathrm{~h}$ light/dark cycle (lights on at 7:00 A.M.). Food and water were provided ad libitum. Rats were weaned 1 week after their arrival, housed collectively by gender, and used between postnatal day 25 (P25) and P42. For stress experiments, rats were restrained for 30 min using individual disposable soft plastic restrainers (Harvard Apparatus, Les Ulis, France), as described previously (Sarrieau et al., 1998), and were allowed a 90 min period of recovery before being deeply anesthetized with isoflurane and decapitated. All experiments were conducted in strict compliance with European directives and French laws on animal experimentation (authorization number 06369).

Hippocampal slice preparation and electrophysiology. Brains from control and stressed rats were sliced $(400 \mu \mathrm{m})$ in the horizontal plane using a Vibratome (Integraslice; Campden Instruments, Leicester, UK). Slices were collected in an ice-cold dissection buffer containing (in mM) 126 $\mathrm{NaCl}, 18 \mathrm{NaHCO}_{3}, 2.5 \mathrm{KCl}, 2.4 \mathrm{MgCl}_{2}, 1.2 \mathrm{CaCl}_{2}, 1.2 \mathrm{NaH}_{2} \mathrm{PO}_{4}$, and 11 glucose, under constant saturation with $95 \% \mathrm{O}_{2} / 5 \% \mathrm{CO}_{2}$. All slices, bearing a cut made between areas CA 3 and CA1 to prevent epileptic activity, were then transferred for $1-4 \mathrm{~h}$ in a storage chamber filled with a temperature-controlled $\left(30^{\circ} \mathrm{C}\right)$ artificial CSF (ACSF) containing (in mM) $126 \mathrm{NaCl}, 18 \mathrm{NaHCO}_{3}, 2.5 \mathrm{KCl}, 1.2 \mathrm{MgCl}_{2}, 2.4 \mathrm{CaCl}_{2}, 1.2 \mathrm{NaH}_{2} \mathrm{PO}_{4}$, and 11 glucose, under constant saturation with $95 \% \mathrm{O}_{2} / 5 \% \mathrm{CO}_{2}$. Slices were then placed in a submersion-type chamber continually perfused $(2 \mathrm{ml} /$ min) with a $30^{\circ} \mathrm{C}$ oxygenated ACSF containing $100 \mu \mathrm{m}$ picrotoxin. Schaffer collateral afferents in stratum radiatum were stimulated $(0.033 \mathrm{~Hz}$, $100 \mu$ s duration) using bipolar tungsten electrodes. The stimulation intensity $(0.20-0.25 \mathrm{~mA})$ was chosen to evoke $40-60 \%$ of the maximal responses. The recording pipette was filled with ACSF and placed in CA1 stratum radiatum. Both the field EPSP (fEPSP) slope and amplitude were measured (graphs depict amplitude). An Axopatch-1D (Molecular Devices, Foster City, CA) was used to record the data, which were filtered at $1-2 \mathrm{kHz}$, digitized at $5 \mathrm{kHz}$ on a DigiData 1200 interface (Molecular Devices), and collected on a personal computer using Clampex 9.2 (Molecular Devices). These data were then analyzed using Clampfit 9.2 (Molecular Devices). In all experiments, DHPG (50 or $100 \mu \mathrm{M}$ ) was applied for $10 \mathrm{~min}$, and its effects on fEPSPs were monitored up to $50 \mathrm{~min}$ after the onset of that application (Rouach and Nicoll, 2003). In the text, calculations of maximal short-term depressive effects of DHPG refer to the $5 \mathrm{~min}$ period showing the highest inhibition of fEPSP responses, whereas calculations on long-term effects of DHPG refer to the last $5 \mathrm{~min}$ of the washout period. In experiments aimed at measuring the impacts of mGluR antagonists, these were present throughout the entire recording procedure. For the estimation of the paired-pulse ratio (PPR), pairs of stimuli (50 ms interval) were delivered every $30 \mathrm{~s}$. The PPR was calculated as the ratio of the amplitude of the fEPSP evoked by the second stimulus on the amplitude of the fEPSP evoked by the first stimulus. To assess the immediate and long-term effects of DHPG on PPRs, these PPRs were measured during the last $5 \mathrm{~min}$ of DHPG application and the last $5 \mathrm{~min}$ of the washout period, respectively. Cumulative probability distributions were based on the last 5 min recordings.

Drugs. 2-Amino-5-phosphonopentanoic acid (AP-5), (RS)-DHPG, 2-methyl-6-(phenylethynyl)-pyridine (MPEP), and 7-(hydroxyimino)cyclopropa $(\beta)$ chromen-1a-carboxylate ethyl ester (CPCCOEt) were from Tocris-Fischer Bioblock (Illkirch, France). Picrotoxin, RU38486 (RU486), and Tween 20 were from Sigma-Aldrich (Saint Quentin Fallavier, France). AP-5 (100 mm) was stocked in 0.1 M NaOH, DHPG (20 $\mathrm{mM})$ and MPEP (10 $\mathrm{mm})$ were stocked in water, and picrotoxin $(100 \mathrm{~mm})$ and CPCCOEt (50 mM) were stocked in DMSO (all stocks kept frozen). Note that DHPG stocks were freshly prepared every week. RU486 (40 $\mathrm{mg} / \mathrm{kg}$ ) was dissolved in water containing a droplet of Tween 20 and injected subcutaneously $(2 \mathrm{ml} / \mathrm{kg})$ in the flanks of control and stressed rats $150 \mathrm{~min}$ before they were killed (i.e., $30 \mathrm{~min}$ before stress). The vehicle solution (water and Tween 20) was administered according to a similar paradigm.

Statistics. All data, presented as mean \pm SEM, were compared by means of Student's $t$ tests (two-group comparisons) and ANOVAs with/ without repeated measures, followed, if significant, by Tukey's multiple comparison tests. In all tests, the significance level was preset to $p<0.05$.

\section{Results}

\section{Acute stress facilitates DHPG-LTD}

Input-output curves of fEPSP amplitude responses to gradual increases in stimulation intensity were similar in slices from control and stressed animals (Fig. 1 A), suggesting that stress did not affect basal synaptic transmission. A 10 min application of $50 \mu \mathrm{M}$ DHPG in control slices promoted an initial depression in excitatory synaptic transmission that returned toward baseline levels by the first $20 \mathrm{~min}$ of the washout period (Fig. $1 B, C$ ). In marked contrast, in slices from stressed animals, the initial depression was followed by LTD (last 5 min of washout: $18 \pm 4 \%, p<0.05$ compared with control slices) (Fig. $1 B, C$ ). Indeed, cumulated data from the entire study showed that $41 \pm 2 \%$ of control slices and $84 \pm 2 \%$ of slices from stressed rats $(p<0.001)$ displayed LTD during the last $5 \mathrm{~min}$ of recordings (supplemental Fig. $\mathrm{S} 1 A, B$, available at www.jneurosci.org as supplemental material) and that the facilitatory effect of stress on DHPG-LTD was independent from the animal gender (supplemental Fig. S1C-F, available at www.jneurosci.org as supplemental material). The inability of $50 \mu \mathrm{M}$ DHPG to elicit LTD in control slices was accounted for by the short latency between slice preparation and recordings (1-4 h; see above) because control slices given $4-7 \mathrm{~h}$ of rest displayed LTD after DHPG application (supplemental Fig. S2, available at www.jneurosci.org as supplemental material).

As opposed to the application of $50 \mu \mathrm{M}$ DHPG, $100 \mu \mathrm{M}$ DHPG promoted LTD in control slices (including in the presence of 100 $\mu \mathrm{M}$ of the NMDAR antagonist AP-5) (supplemental Fig. S3A, available at www.jneurosci.org as supplemental material), the amplitude of which was similar to that measured in slices from stressed rats ( $15 \pm 4$ and $26 \pm 5 \%$, respectively) (supplemental Fig. S3B, available at www.jneurosci.org as supplemental material). These results indicate that the stress paradigm used herein solely potentiates the effects of a subthreshold activation of mGluRs to induce LTD.

We next analyzed PPRs after $50 \mu \mathrm{M}$ DHPG application to slices from control and stressed animals. The respective baseline PPRs did not differ between the two groups of slices (1.28 \pm 0.09 and $1.30 \pm 0.06$ for control and stress, respectively; $n=8$ in each group). Besides, although DHPG application affected PPRs in control slices $\left(F_{(2,21)}=5.58 ; p<0.05\right)$ and in slices from stressed rats $\left(F_{(2,21)}=5.18 ; p<0.05\right)$, post hoc comparisons revealed that the PPR increased during but not after that application in both slice groups (Fig. 2). This suggests that the facilitation of DHPGLTD is not associated with changes in presynaptic release probability.

\section{The facilitatory effect of stress on DHPG-LTD is mediated by GRs}

Because the restraint paradigm used herein promotes sustained corticosterone release (Sarrieau et al., 1998), we investigated whether GRs are involved in the LTD elicited by $50 \mu \mathrm{M}$ DHPG. To this aim, control and stressed rats were pretreated (150 min before they were killed, i.e., 30 min before stress) with the GR antagonist RU486 (40 mg/kg) or its vehicle. Analyses of the longterm effects of $50 \mu \mathrm{M}$ DHPG application to slices from vehicleinjected animals (Fig. $3 A, B$ ) confirmed that stress facilitates LTD (18 $\pm 5 \% ; p<0.01$ for the difference with controls). Besides, RU486 pretreatment selectively abolished the impact of stress on DHPG-LTD (Fig. 3C,D). Of note is the observation that in slices 


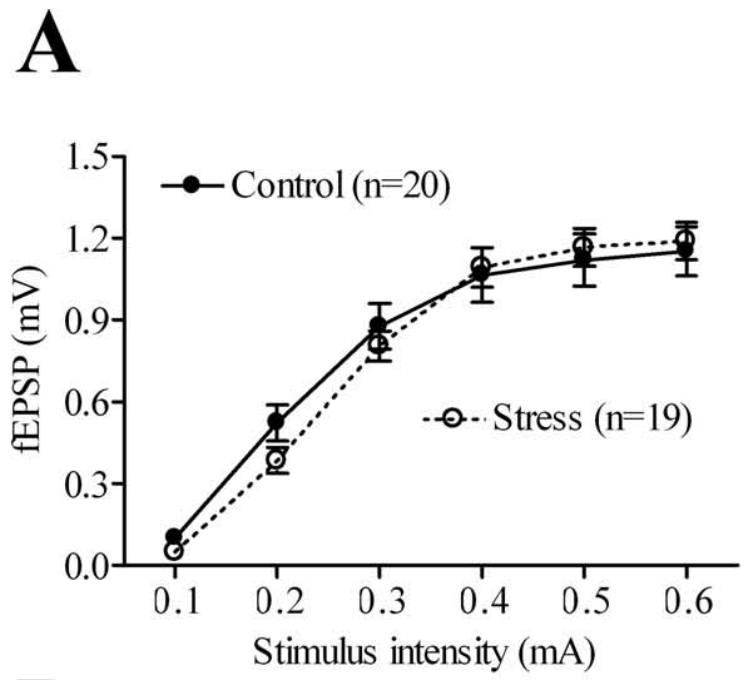

B
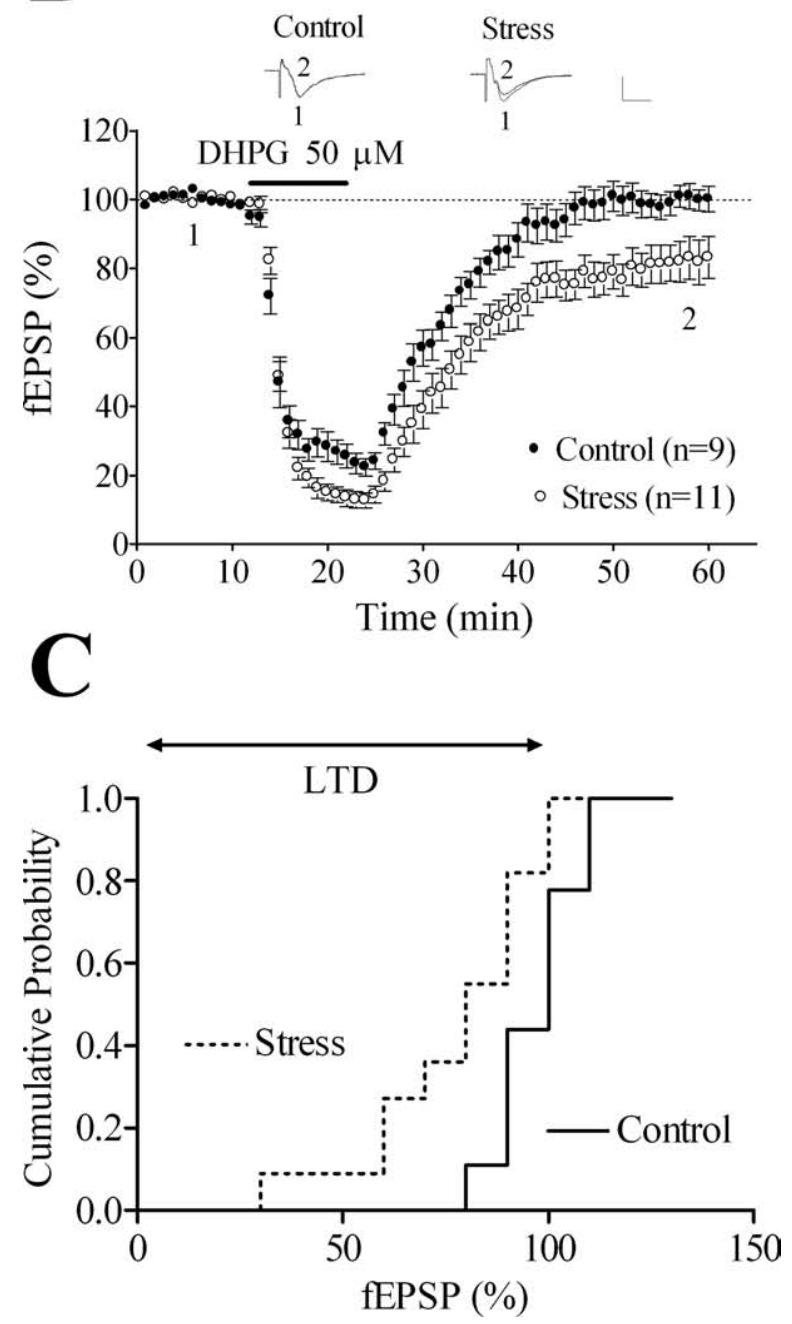

Figure 1. Acute stress facilitates mGluR-LTD in the rat hippocampal CA1 region. $\boldsymbol{A}$, fEPSP responses to increasing stimulus intensities do not differ between slices from control and stressed rats. $B, A 10$ min application of $50 \mu \mathrm{m}$ DHPG elicits LTD in slices from stressed but not from control rats. Whether analyzed during the last 10 or 20 min of recordings, stress, but not the stress $\times$ time interaction, proves significant $\left(F_{(1,162)}=7.64, p=0.013\right.$ and $F_{(1,342)}=9.05, p=0.008$, respectively). Inset, Representative fEPSPs taken at the time indicated on the graph below. Calibration: $0.5 \mathrm{mV}, 10$ ms. C, Cumulative probability distribution of the normalized fEPSPs represented as averages in $\boldsymbol{B}$. In this and subsequent figures, each point is the average of two successive responses, and dashed lines represent $100 \%$ of baseline. Data are represented as mean \pm SEM.

\section{A}
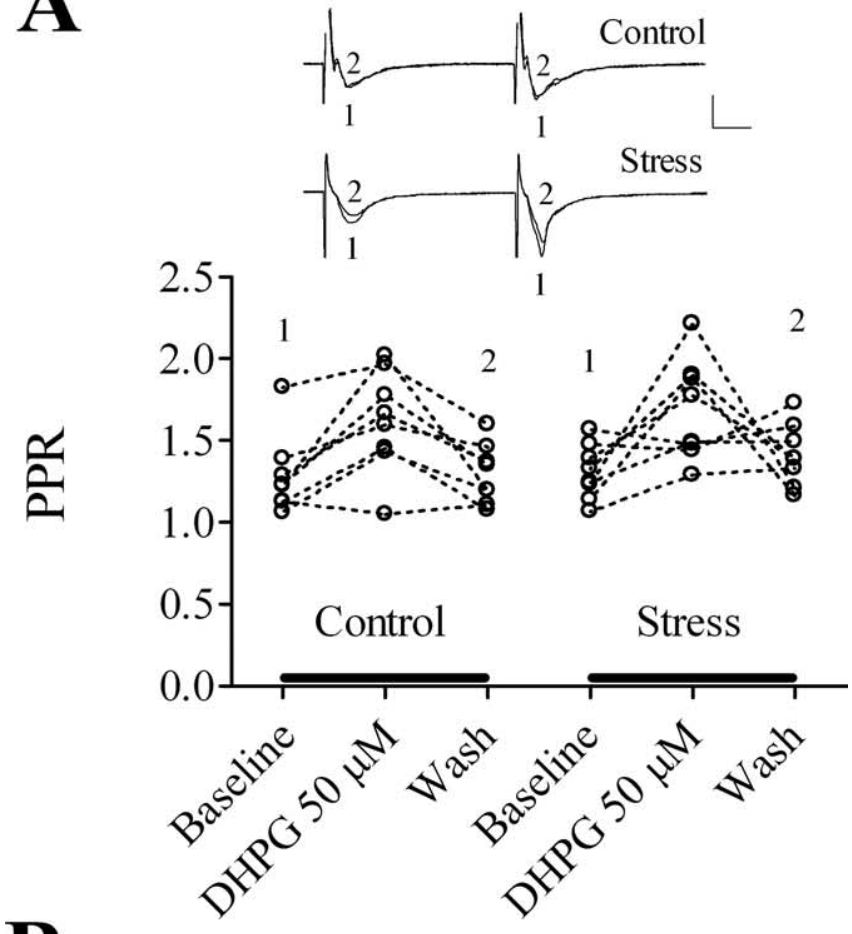

B

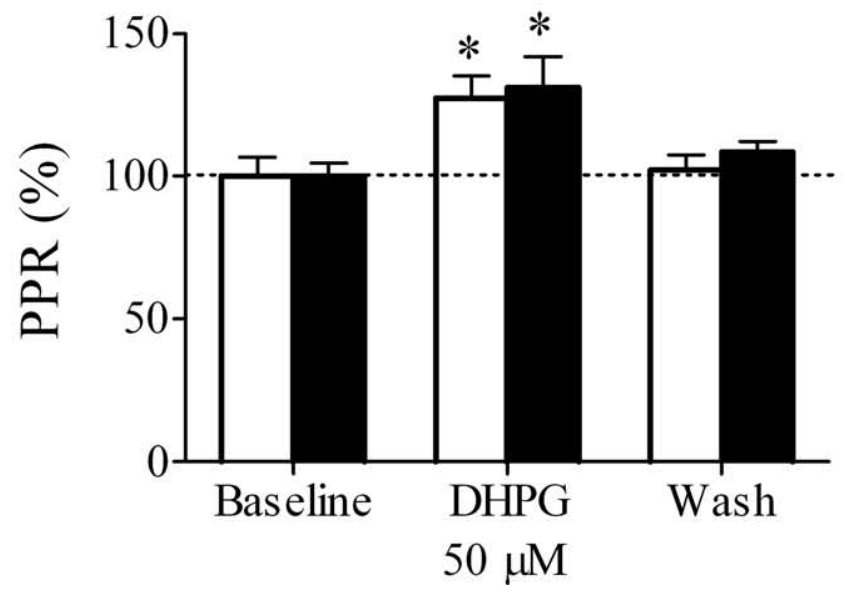

Figure 2. The facilitatory effect of acute stress on DHPG-LTD is not associated with a change in the PPR. $A$, Individual PPR absolute values before (baseline), during (DHPG $50 \mu \mathrm{M}$ ), and after (wash) a 10 min application of DHPG to slices from control and stressed rats ( $n=8$ per group). Inset, Representative fEPSPs taken at the time indicated on the graph below. Calibration: 0.5 $\mathrm{mV}, 10 \mathrm{~ms}$. B, Percentage of PPR changes from baseline during (DHPG $50 \mu \mathrm{m}$ ) and after (wash) a 10 min application of DHPG to slices from control and stressed rats. The PPR increases during $\left({ }^{*} p<0.05\right)$ but not after DHPG application in both slice groups. Data are represented as mean \pm SEM.

from stressed rats, RU486 pretreatment did not affect the maximal amplitude of the short-term inhibition triggered by DHPG ( $82 \pm 4$ and $71 \pm 4 \%$ of baseline levels in vehicle- and RU486preteated groups, respectively) (Fig. 3C), indicating a selective involvement of GRs on LTD expression.

Together, these results indicate that the facilitatory effect of stress on DHPG-LTD requires corticosterone release and, in turn, GR stimulation. 
A
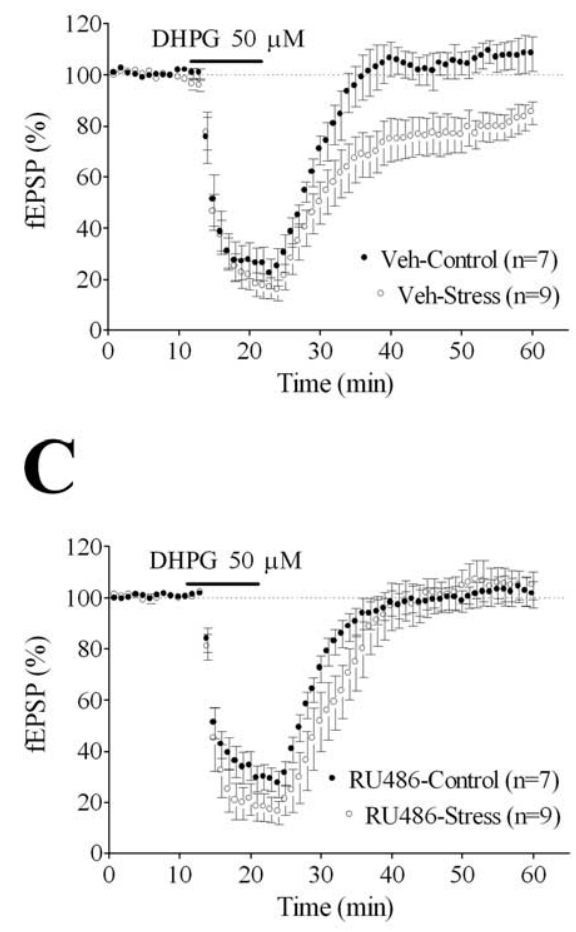

B

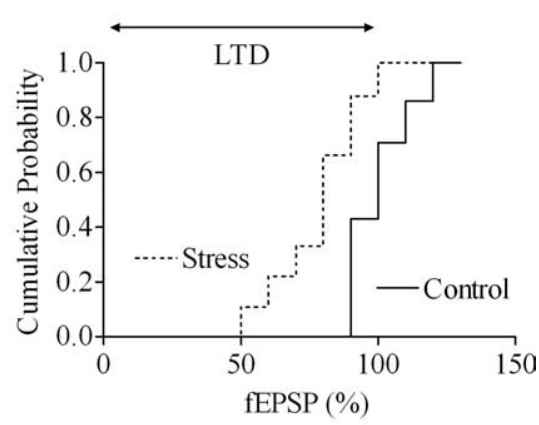

D

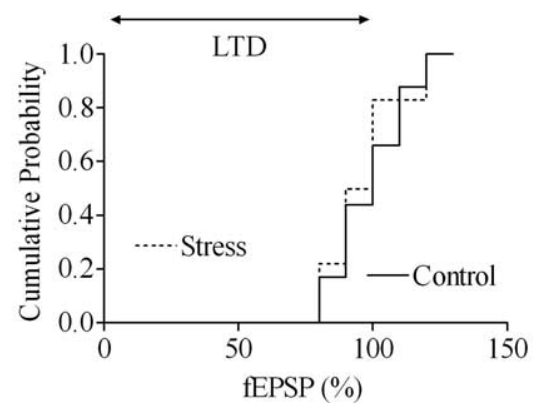

Figure 3. The facilitatory effect of acute stress on DHPG-LTD is mediated by GRs. $A, A 10$ min application of $50 \mu \mathrm{m}$ DHPG elicits LTD in slices from stressed but not from control rats pretreated with vehicle (Veh). Whether analyzed during the last 10 or $20 \mathrm{~min}$ of recordings, stress, but not the stress $\times$ time interaction, proves significant $\left(F_{(1,126)}=11.72, p=0.004\right.$ and $F_{(1,266)}=10.09$, $p=0.007$, respectively). $\boldsymbol{B}$, Cumulative probability distribution of the normalized fEPSPs represented as averages in $\boldsymbol{A} . \boldsymbol{C}, A 10 \mathrm{~min}$ application of $50 \mu \mathrm{m}$ DHPG fails to induce LTD in slices from stressed rats pretreated (30 min before stress) with RU486. D, Cumulative probability distribution of the normalized fEPSPs represented as averages in $C$. Data are represented as mean \pm SEM.

\section{The facilitatory effect of stress on DHPG-LTD involves mGluR1}

We next evaluated the respective influences of the selective mGluR1 antagonist CPCCOEt $(50 \mu \mathrm{M})$ (Litschig et al., 1999) and the selective mGluR5 antagonist MPEP $(10 \mu \mathrm{M})$ (Gasparini et al., 1999) on fEPSP responses to DHPG application in slices from control and stressed animals. In control slices, the maximal amplitude of the DHPG initial inhibitory effect varied with the treatments $\left(F_{(2,17)}=4.43 ; p<0.05\right)$. Thus, such maximal amplitude was decreased after either CPCCOEt (50 $\pm 3 \%$ of baseline levels; $p<0.05)$ or MPEP $(45 \pm 7 \%$ of baseline levels; $p<0.05)$ compared with vehicle-treated slices ( $71 \pm 7 \%$ of baseline levels) (Fig. $4 A)$. In slices from stressed rats, treatments affected the extent to which DHPG exerted its maximal short-term effect $\left(F_{(2,23)}=\right.$ 7.90; $p<0.01$ ) with CPCCOEt (38 $\pm 9 \%$ of baseline levels; $p<$ 0.01 ) but not MPEP ( $65 \pm 5 \%$ of baseline levels), reducing that response compared with vehicle-treated slices $(71 \pm 5 \%$ of baseline levels) (Fig. 4C). Long-term effects of DHPG, absent in control slices (Fig. $4 A, B$ ), varied with the treatments in slices from stressed rats $\left(F_{(2,23)}=3.65 ; p<0.05\right)$, with CPCCOEt $(1 \pm 3 \%$; $p<0.05)$, but not MPEP (14 $\pm 3 \%$ ), preventing DHPG-LTD $(22 \pm 6 \%$ in vehicle-treated slices) (Fig. 4C,D).

Thus, these experiments demonstrate that mGluR1, but not mGluR5, mediates DHPG-LTD in slices from stressed rats.

\section{Discussion}

The present results show that stress, through corticosterone stimulation of GRs, lowers the threshold for mGluR1-dependent DHPG-LTD in the hippocampal CA1 region.
So far, the impact of acute stressors and/or manipulations of the hypothalamo-pituitary-adrenal axis on hippocampal CA1 homosynaptic plasticity have focused on NMDAR-dependent LTP and LTD. In vitro and in vivo findings indicate that LFS (1-3 Hz, $15 \mathrm{~min}$ ) triggers LTD in stressed animals while proving ineffective in the long term in control animals (Kim et al., 1996; Xu et al., 1997; Yang et al., 2004). Because acute stress also impairs synaptic potentiation (Foy et al., 1987; Shors et al., 1989; Xu et al., 1997; Alfarez et al., 2002), it has been proposed that stress has metaplastic properties (Kim and Diamond, 2002). Metaplasticity refers to the resetting of the respective thresholds for LTP and/or LTD without any permanent change in synaptic efficacy (Abraham and Bear, 1996). In this context, our observation that an ineffective concentration of DHPG in control slices proved effective in promoting LTD in slices from stressed animals strongly suggests that stress metaplastic effects in the hippocampal CA1 region extend to mGluR-LTD. When the DHPG concentration was effective in triggering LTD in control slices, stress did not further enhance LTD. This indicates that stress targets the mechanisms allowing the expression of DHPG-LTD, the efficiencies of which are yet set to their maximal level by stress.

Studies of PPR changes have suggested that, depending on the developmental stage, presynaptic $(<\mathrm{P} 15)$ or postsynaptic $(>\mathrm{P} 21)$ mechanisms underlie the expression of DHPG-LTD in rats (Huber et al., 2000; Nosyreva and Huber, 2005; Zhang et al., 2006) (but see Fitzjohn et al., 2001; Moult et al., 2006). In our preparation, DHPG application to slices from stressed adolescent $(>\mathrm{P} 21)$ rats elicited a rapid increase in PPR but was without effect on long-term PPR. This result thus suggests that the facilitatory influence of stress on the expression of DHPG-LTD involves postsynaptic mechanisms.

Circulating corticosterone concentrations and LTP amplitude in hippocampal CA1 follow an inverted U-shape relationship (Diamond et al., 1992). Conformingly, pretreatment of stressed rats with a GR blocker prevents both the inhibitory influence of stress on NMDA-LTP and stress-elicited facilitation of NMDALTD (Xu et al., 1998; Yang et al., 2004). This GR-mediated facilitatory influence of stress on NMDA-LTD extends to DHPG-LTD because pretreatment with a GR antagonist prevented the longterm effects of DHPG in slices from stressed rats. The lack of effect of GR blockade in controls clearly indicates that restraintelicited corticosterone release is responsible for the facilitation of DHPG-LTD.

The quest for the identity of the mGluR subtype involved in the expression of DHPG-LTD has provided contradictory results (Gasparini et al., 1999; Huber et al., 2001; Faas et al., 2002; Hou and Klaan, 2004; Nosyreva and Huber, 2005). Beside discrepancies likely attributable to differences in animal species/age and DHPG concentrations, a recent electrophysiological and biochemical study has shown that the duration of exposure to the 
antagonists and to DHPG is an important variable (Volk et al., 2006). Taking into account that variable, it was reported that mGluR1 or mGluR5 mediates the induction of DHPG-LTD, whereas mGluR1 is fully responsible for the expression of that LTD (Volk et al., 2006). Using a similar pharmacological approach (i.e., continuous presence of the antagonists throughout the experiment), we found that mGluR1 blockade diminished the amplitude of the DHPG acute inhibitory effect and prevented the facilitatory influence of stress on DHPG-LTD. Because mGluR1 or mGluR5 blockade diminished the acute inhibitory influence of DHPG in controls, our results indicate that stress, through corticosterone release and GR stimulation, favors a selective stimulation of mGluR 1 at the expense of mGluR5. The observation that mGluR1 as opposed to mGluR5 stimulation does not potentiate NMDA currents in CA1 (Mannaioni et al., 2001) in turn suggests that the aforementioned effects of stress are independent from NMDARs.

Repeated/chronic stress is associated with a facilitation of LFS-elicited LTD in hippocampal CA1, a change prevented by chronic antidepressant treatment (Von Frijtag et al., 2001). Moreover, using a different stimulus protocol (paired-pulse LFS) in adult animals, chronic stress was found to facilitate LTD in hippocampal CA1 (Holderbach et al., 2007). Again, such facilitation vanished if animals were treated with a chronic antidepressant regimen (Holderbach et al., 2007). These results suggest that plasticity changes occurring with repeated/ chronic exposure to stress may reflect a lack of adaptation to the stressor. Bearing in mind the results from the present study as well as the anxiolytic and/or antidepressant profiles of several type $1 \mathrm{mGluR}$ ligands (Spooren et al., 2003), future experiments should test whether CA1 DHPG-LTD is sensitive to chronic stress as do other forms of plasticity (see above) and, if so, whether such a sensitivity is adaptive or not.

\section{References}

Abraham WC, Bear MF (1996) Metaplasticity: the plasticity of synaptic plasticity. Trends Neurosci 19:126-130.

Alfarez DN, Wiegert O, Joëls M, Krugers HJ (2002) Corticosterone and stress reduce synaptic potentiation in mouse hippocampal slices with mild stimulation. Neuroscience 115:1119-1126.

Bolshakov VY, Siegelbaum SA (1994) Postsynaptic induction and presynaptic expression of hippocampal long-term depression. Science 264:1148-1152.

Coussens CM, Kerr DS, Abraham WC (1997) Glucocorticoid receptor activation lowers the threshold for NMDA-receptor-dependent homosynaptic long-term depression in the hippocampus through activation of voltage-dependent calcium channels. J Neurophysiol 78:1-9.

De Kloet ER (1991) Brain corticosteroid balance and homeostatic control. Front Neuroendocrinol 12:95-164.

De Kloet ER, Joëls M, Holsboer F (2005) Stress and the brain: from adaptation to disease. Nat Rev Neurosci 6:463-475.

Diamond DM, Bennett MC, Fleshner M, Rose GM (1992) Inverted-U rela-
B

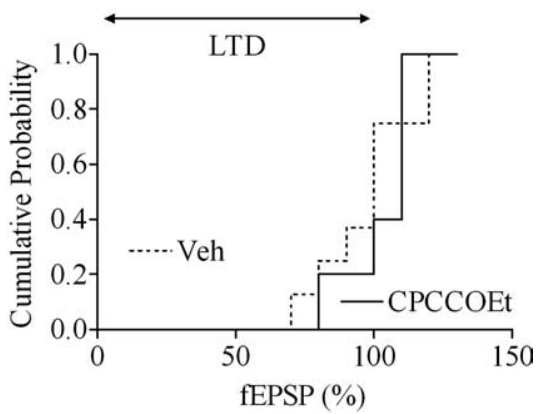

D

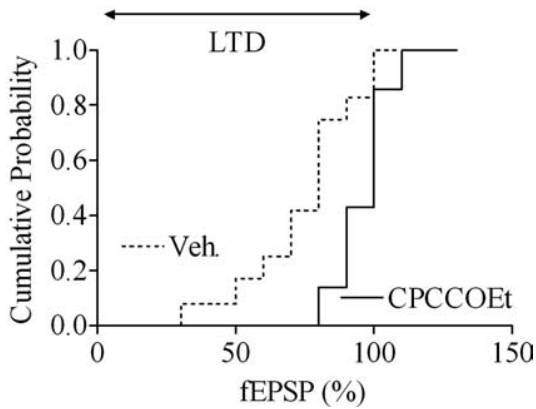

- Veh-Stress $(\mathrm{n}=12)$

CPCCOEt-Stress $(\mathrm{n}=7)$

MPEP-Stress $(\mathrm{n}=7)$

fEPSP (\%) 50

Figure 4. DHPG-LTD in slices from stressed rats is mediated by mGluR1. $\boldsymbol{A}$, The short-term inhibitory effect of a $10 \mathrm{~min}$

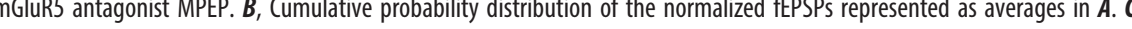
CPCCOEt-pretreated slices. $\boldsymbol{D}$, Cumulative probability distribution of the normalized fEPSPs represented as averages in $\boldsymbol{C}$. For clarity, MPEP is not presented in $\boldsymbol{B}$ and $\boldsymbol{D}$. Veh, Vehicle. Data are represented as mean \pm SEM.

tionship between the level of peripheral corticosterone and the magnitude of hippocampal primed burst potentiation. Hippocampus 2:421-430.

Faas G, Adwanikar H, Gereau RW, Saggau P (2002) Modulation of presynaptic calcium transients by metabotropic glutamate receptor activation: a differential role in acute depression of synaptic depression and long-term depression. J Neurosci 22:6885-6890.

Fitzjohn SM, Kingston AE, Lodge D, Collingridge GL (1999) DHPGinduced LTD in area CA1 of juvenile rat hippocampus; characterisation and sensitivity to novel mGlu receptor antagonists. Neuropharmacology 38:1577-1583.

Fitzjohn SM, Palmer MJ, May JER, Neeson A, Morris SAC, Collingridge GL (2001) A characterisation of long-term depression induced by metabotropic glutamate receptor activation in the rat hippocampus in vitro. J Physiol (Lond) 537:421-430.

Foy MR, Stanton ME, Levine S, Thompson RF (1987) Behavioral stress impairs long-term potentiation in rodent hippocampus. Behav Neural Biol 48:138-149.

Gasparini F, Lingenhohl K, Stoehr N, Flor PJ, Heinrich M, Vranesic I, Biollaz M, Allgeier H, Heckendorn R, Urwyler S, Varney MA, Johnson EC, Hess SD, Rao SP, Sacaan AI, Santori EM, Velicelebi G, Kuhn R (1999) 2-Methyl-6-(phenylethynyl)-pyridine (MPEP), a potent, selective and systemically active mGlu5 receptor antagonist. Neuropharmacology 38:1493-1503.

Holderbach R, Clark K, Moreau JL, Bischofberger J, Normann C (2007) Enhanced long-term synaptic depression in an animal model of depression. Biol Psychiatry, in press.

Hou L, Klann E (2004) Activation of the phosphoinositide 3-kinase-Aktmammalian target of rapamycin signaling pathway is required for 
metabotropic glutamate receptor-dependent long-term depression. J Neurosci 24:6352-6361.

Huber KM, Kayser MS, Bear MF (2000) Role for rapid dendritic protein synthesis in hippocampal mGluR-dependent long-term depression. Science 288:1254-1256.

Huber KM, Roder JC, Bear MF (2001) Chemical induction of mGluR5- and protein synthesis-dependent long-term depression in hippocampal area CA1. J Neurophysiol 86:321-325.

Kim JJ, Diamond DM (2002) The stressed hippocampus, synaptic plasticity and lost memories. Nat Rev Neurosci 3:453-462.

Kim JJ, Foy MR, Thompson RF (1996) Behavioral stress modifies hippocampal plasticity through N-methyl-D-aspartate receptor activation. Proc Natl Acad Sci USA 93:4750-4753.

Litschig S, Gasparini F, Rueegg D, Stoehr N, Flor PJ, Vranesic I, Prezeau L, Pin JP, Thomsen C, Kuhn R (1999) CPCCOEt, a noncompetitive metabotropic glutamate receptor 1 antagonist, inhibits receptor signaling without affecting glutamate binding. Mol Pharmacol 55:453-461.

Malenka RC, Bear MF (2004) LTP and LTD: an embarrassment of riches. Neuron 44:5-21.

Mannaioni G, Marino MJ, Valenti O, Traynelis SF, Conn PJ (2001) Metabotropic glutamate receptors 1 and 5 differentially regulate CA1 pyramidal cell function. J Neurosci 21:5925-5934.

McEwen BS (2000) The neurobiology of stress: from serendipity to clinical relevance. Brain Res 886:172-189.

Moult PR, Gladding CM, Sanderson TM, Fitzjohn SM, Bashir ZI, Molnar E, Collingridge GL (2006) Tyrosine phosphatases regulate AMPA receptor trafficking during metabotropic glutamate receptor-mediated long-term depression. J Neurosci 26:2544-2554.

Nosyreva ED, Huber KM (2005) Developmental switch in synaptic mechanisms of hippocampal metabotropic glutamate receptor-dependent longterm depression. J Neurosci 25:2992-3001.

Oliet SH, Malenka RC, Nicoll RA (1997) Two distinct forms of long-term depression coexist in CA1 hippocampal pyramidal cells. Neuron 18:969-982.

Palmer MJ, Irving AJ, Seabrook GR, Jane DE, Collingridge GL (1997) The group I mGlu receptor agonist DHPG induces a novel form of LTD in the CA1 region of the hippocampus. Neuropharmacology 36:1517-1532.
Rouach N, Nicoll RA (2003) Endocannabinoids contribute to short-term but not long-term mGluR-induced depression in the hippocampus. Eur J Neurosci 18:1017-1020.

Sarrieau A, Chaouloff F, Lemaire V, Mormède P (1998) Comparison of the neuroendocrine responses to stress in outbred, inbred and F1 hybrid rats. Life Sci 63:87-96.

Shors TJ, Seib TB, Levine S, Thompson RF (1989) Inescapable versus escapable shock modulates long-term potentiation in the rat hippocampus. Science 244:224-226.

Spooren W, Ballard T, Gasparini F, Amalric M, Mutel V, Schreiber R (2003) Insight into the function of group I and group II metabotropic glutamate (mGlu) receptors: behavioural characterization and implications fort the treatment of CNS disorders. Behav Pharmacol 14:257-277.

Volk LJ, Daly CA, Huber KM (2006) Differential roles for group 1 mGluR subtypes in induction and expression of chemically-induced hippocampal long-term depression. J Neurophysiol 95:2427-2438.

Von Frijtag JC, Kamal A, Reijmers LG, Schrama LH, van den Bos R, Spruijt BM (2001) Chronic imipramine treatment partially reverses the longterm changes of hippocampal synaptic plasticity in socially stressed rats. Neurosci Lett 309:153-156.

Wiegert O, Pu Z, Shor S, Joëls M, Krugers H (2005) Glucocorticoid receptor activation selectively hampers $\mathrm{N}$-methyl-D-aspartate receptor dependent hippocampal synaptic plasticity in vitro. Neuroscience 135:403-411.

Xu L, Anwyl R, Rowan MJ (1997) Behavioural stress facilitates the induction of long-term depression in the hippocampus. Nature 387:497-500.

Xu L, Holscher C, Anwyl R, Rowan MJ (1998) Glucocorticoid receptor and protein/RNA synthesis-dependent mechanisms underlie the control of synaptic plasticity by stress. Proc Natl Acad Sci USA 95:3204-3208.

Yang CH, Huang CC, Hsu KS (2004) Behavioral stress modifies hippocampal synaptic plasticity through corticosterone-induced sustained extracellular signal-regulated kinase/mitogen-activated protein kinase activation. J Neurosci 24:11029-11034.

Zhang XL, Zhou ZY, Winterer J, Müller W, Stanton PK (2006) NMDAdependent, but not group I metabotropic glutamate receptor-dependent, long-term depression at Schaffer collateral-CA1 synapses is associated with long-term reduction of release from the rapidly recycling presynaptic vesicle pool. J Neurosci 26:10270-10280. 